\title{
Research of Chinese Public Sector Managers Leadership Based on the Fuzzy Comprehensive Evaluation Method
}

\author{
Xiaoli Zhang* and Changjiang Liu
}

Management College of China, West Normal University, Sichuan, 637009, China

\begin{abstract}
Leaders in public sectors should have such qualities as skills for future management, foreseeing thinking, promoting social comprehensive development, coordinating in creating harmonious society, solving problems, creating new advantages, strictly and lawfully implementing and closely uniting cadres and people. They should continuously improve their capability in serving the public and handling crisis as well as their non-authoritative influence. Therefore, the establishment of a comprehensive Public Sector Managers Leadership Model that provides a new perspective and a new way to study the quality of public sector managers, assessment training and selection improved. In this paper, based on the research of the theory of leadership, we established a leadership evaluation model and introduce fuzzy comprehensive evaluation method and AHP to quantify the evaluation factors which contain the characteristics of fuzziness and complexity science. We have carried on the instance analysis.
\end{abstract}

Keywords: AHP, fuzzy comprehensive evaluation method, leadership, model of leadership, public sector managers.

\section{INTRODUCTION}

Many studies have found that leadership has a significant positive effect on the performance or success of the individual, team, or organization. Organizational capacity building and the competitive advantage of the organization promoting are closely linked to the leadership development [1]. Spending more in leadership development will gain stronger the ability of organization, more effective organization and higher organization performance. Because leadership is a key factor in the success of an individual or organization, many organizations put its future development on leaders and common vision goals of talent team. At present, China is in the period of social transformation and rapid development of economy; [2] modernization construction is more onerous, more complicated relations in interests, the new situation and new problems appear constantly, the rapid development of science and technology, all above put forward the severe challenges such as the ability of innovation and development challenge, the challenge of the administrative ability [3], the challenges of crisis management capabilities, challenges and other management tools and methods for the qualities and abilities of the public sector leadership at all levels, especially these local leading cadres who leading the local economic and social development.

According to the survey, in today's era of global competition, organizational leaders leadership deficiency is a global problem Jack Welch once said: "Surviving In this knowledge economy era by competition, the only way to succeed is constantly improve their ability, enhance their comprehensive quality, continuous improve their leadership [4]. If an organization especially enterprises want to get a lasting success, it must pay attention to leadership, to adapt to the change and maintain a competitive advantage."

Worldwide demand for leadership is far more than its supply capacity, especially China is the highest percentage of country that lack the leadership of the highest proportion of people lacking. $47 \%$ of companies surveyed believe they lack leadership talent, and $61 \%$ of Chinese companies think that the reason why there is no way to implement the plan of the reserve and the training of leaders is that they lack of the culturist. Enterprises still so, the administration is more selfevident [5]. "Leadership achieves the great organization" The seriousness lack of leadership makes the study of how to improve the administrative leadership imperative.

In this paper, we introduce the frontier theoretical system of leadership model into the public sector leadership talent management and development. We introduce the fuzzy comprehensive evaluation method, construct Public Sector Managers Leadership fuzzy comprehensive evaluation model, and do the research for public sector leadership model. We intend to enrich the theory, broaden the public sector leadership talent management and development train of thought to promote the public sector of the competitiveness and performance

\section{LEADERSHIP RESEARCH STATUS}

Leadership mean the ability of the leader, it refers leader affect individuals or groups to achieve the stated objectives of behavior under certain environmental conditions and power [6]. There are a lot of exploration and description to leadership in the management area, mainly focused in three areas: business leadership, technology leadership and the public sector (government) leadership. The research on pub- 
lic sector (government) leadership dominates the current leadership in research.

In fact, there is little research on public sector leadership, and by looking for the article about this, we can only find the essay "The composition and the way of improvement of effective leadership" which understand the leadership from the point of power influence and non-power influence [7]. While with the improvement of the Chinese market economy and the transformation of government functions, and the goal of the scientific outlook on development and building a harmonious society, research how to improve public sector leadership has become a new topic. Now the research about leadership in our country contains the following factors:

(1) Leadership Competency under Different organizational context; (2) Through the investigation tracking and simulation methods to demonstrate; (3) Research on leadership effectiveness index system should be further improved; (4) Few impact study based leadership assessment and evaluation model for companies.

The research group "technology leadership" of Chinese Academy of Sciences discussed and proposed the Five Leadership Model to guide the Chinese Academy of training and leadership at all levels of practice: Leadership foresight force, Leadership charisma, Leadership Influence, leadership determination and leadership control.

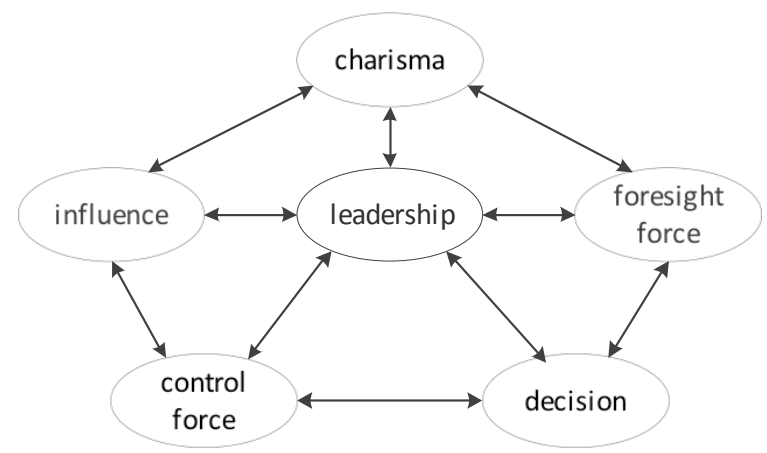

Fig. (1). The five leadership model.

\section{THE EXISTING LEADERSHIP EVALUATION METHODS}

The level of leadership of the managers is measured through evaluation. The assessment shows managers' leadership level and indicates the direction for the improvement of public sector manager leadership [8]. We can find that the evaluation of leadership plays an extremely important role in improving public sector manager leadership. Through long time practice and development, there appear more and more evaluation methods, to enhance comprehensive and constantly improve the credibility of evaluation results [9]. At present, the academia and the practice of evaluation methods mainly include the following

\section{(1) The traditional evaluation method}

Mainly includes: critical incident method is to note a very good or very poor job that has done by reviewer by the subordinates, peers or superiors. Interview is that in the interview process, the leaders were asked a series of pre-prepared questions to evaluate their level of leadership based on their answer. Observation is another commonly used structured or unstructured assessment tools, observation can get information about the behavior of the leader, but systematic observation and record the behavior of leader is very difficult and time-consuming.

\section{(2) 360 Degree Feedback}

360 Degree Feedback is often referred among the assessment questionnaire. The evaluation method is being evaluated by their subordinates, peers, superiors, and external personnel such as customer to fill out evaluations and so on to evaluate the assessed behavior and skills.

\section{(3) Self-Appraisals}

Self-assessment method flourished in the Internet. Selfassessment is essentially an informal assessment. It provides a measure of whether they have become an effective leader or having a corresponding method for assessing the ability of persons. It provides a leadership assessment tool. This selfassessment tool measures the success of the leadership on 25 key indicators.

\section{(4) Assessment center assessment method}

Assessment Centre uses a variety of methods to assess leadership skills and can effectively enhance its potential [10]. Establish assessment center can make leaders and their superiors to see their actual performance and its goal, and then make a more objective evaluation of their ability.

Public sector leadership formula can be briefly summarized as the first five elements and with 6 elements in the product:

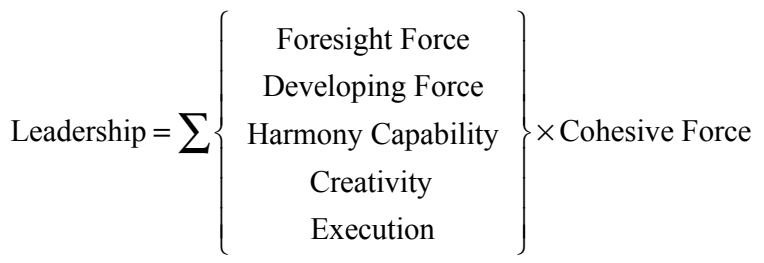

\section{INTRODUCE THE PRINCIPLE OF FUZZY COMPREHENSIVE EVALUATION}

The principle of fuzzy comprehensive evaluation is based on fuzzy transformation and the principle of maximum membership, consider and evaluate the various factors to be evaluated thing related to the evaluation made by its comprehensive. It can solve the problem with the vagueness of the decision which the traditional methods difficult to resolve. It is an effective decision support methods in the economic, social, management and other activities.

The steps of fuzzy comprehensive evaluation: at first, determine the evaluation index system of fuzzy $U=\left\{u_{1}, u_{2}, u_{3} \cdots \cdots u_{m}\right\}$, then determine the index level evaluation set $V=\left\{v_{1}, v_{2}, v_{3} \cdots \cdots v_{n}\right\}$. Determine the membership degree that each factor for each evaluation grade. Qualitative index of the membership degree is obtained with fuzzy statistical method. Fuzzy statistics requests the evaluation team members who participate in evaluation to define the level of index $U$ according to the defined level of evaluation index set $V$, then statistics obtained membership degree $r_{i j}$ and get the factor evaluation matrixes 


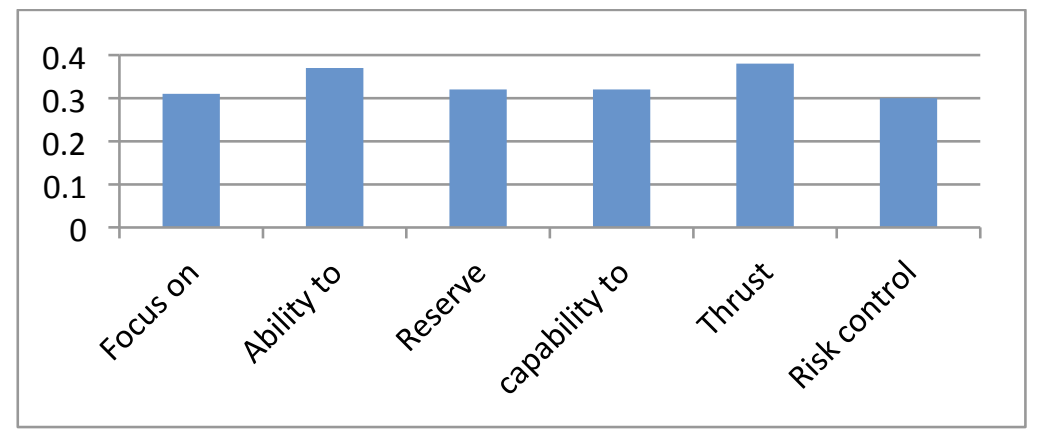

Fig. (2). Weight distribution histogram.

$R=\left(r_{i j}\right)(i=1,2 \cdots m ; j=1,2 \cdots n)$. Next we use the analytic hierarchy process to determine the weight of each factor $W=\left[w_{1}, w_{2}, w_{3} \cdots \cdots w_{m}\right]$. Finally, we take the fuzzy transformation, comprehensive evaluation. According to the answer $Y=W \times R$, take specific evaluation of the model.

\section{MANAGERS LEADERSHIP EVALUATION MODEL BASED ON FUZZY COMPREHENSIVE EVALUATION}

In the fuzzy comprehensive evaluation method, the first to clear evaluation index, the factors of evaluation grades and weights, and then follow the steps below to construct the evaluation model of the paper. Factors Sets $U$, evaluation set $V$ and judgment matrix $R$ and the index weight set $W$ consist the main part of the model, the specific steps in detail are as following:

\section{(1) Determine the evaluation factor set $U$}

We set the number of evaluation index with $\mathrm{m}$, and use $U=\left\{u_{1}, u_{2}, u_{3} \cdots \cdots \cdot u_{m}\right\}$ represents evaluation index of the object that being estimated.

(2) Determine the evaluation set $V$ of the evaluation index

Set comment sets $V=\left\{v_{1}, v_{2}, v_{3} \cdots \cdots v_{n}\right\}$ and use it to represent the level of reviews of each index. According to the grade level of the evaluation index that have been established in the paper, we set $V=\{$ excellent, good, general, poor, very poor $\}$

\section{(3) Build the weights}

The important of the various factors are different. We should take special attention to the important factors and a little attention to the general factors. In order to reflect the importance of the various factors, we should assign corresponding weights $a_{k}(k=1,2, \cdots, 5)$ to various factors.

$a_{k} \geq 0, \sum_{k=1}^{5} a_{k}=1$.

For example we set $A=\{0.3,0.2,0.15,0.1,0.25\}$.

\section{(4) Fuzzy Evaluation}

We set the fuzzy evaluation matrix as $R=\left(r_{i j}\right)(i=1,2 \cdots m ; j=1,2 \cdots n)$. The $r_{i j}$ refers to the membership degree that each factor $U_{i}$ for each evaluation grade $V_{j}$
We select the membership degree functions to compute $r_{i j}$ and use $R=\left\{r_{i 1}, r_{i 2}, \cdots, r_{i n}\right\}$ refers to the evaluation set of $U_{i}$.

We can get the single factor fuzzy evaluation matrix:

$$
R=\left[\begin{array}{llll}
r_{11} & r_{12} & \mathrm{~L} & r_{1 n} \\
r_{21} & r_{22} & \mathrm{~L} & r_{2 n} \\
\mathrm{~L} & \mathrm{~L} & \mathrm{~L} & \mathrm{~L} \\
r_{m 1} & r_{m 2} & \mathrm{~L} & r_{m n}
\end{array}\right]
$$

It said the evaluation of the fuzzy relationship between the whole set of factors. We can get it from the single factor evaluation matrix that the row $i$ of $R$ reflects the factors $i$ is $u_{i}$. It influences the degree that judgment objects take each evaluation element. The line $j$ of $R$ reflects the degree of all of the elements that influence the taken of element $j$ of evaluation. Then we get the fuzzy comprehensive evaluation model:

$$
\begin{aligned}
& B=A \bullet R=\left(a_{1}, a_{2}, \mathrm{~L}, a_{m}\right) \bullet\left[\begin{array}{llll}
r_{11} & r_{12} & \mathrm{~L} & r_{1 n} \\
r_{21} & r_{22} & \mathrm{~L} & r_{2 n} \\
\mathrm{~L} & \mathrm{~L} & \mathrm{~L} & \mathrm{~L} \\
r_{m 1} & r_{m 2} & \mathrm{~L} & r_{m n}
\end{array}\right]=\left(b_{1}, b_{2}, \mathrm{~L}, b_{n}\right) \\
& {\left[r_{i 1}, r_{i 2}, \mathrm{~L}, r_{i n}\right]=\left[w_{i 1}, w_{i 2}, \mathrm{~L} \quad w_{i k}\right]\left[\begin{array}{cccc}
0 & 1 & \mathrm{~L} & 0 \\
0 & 0 & \mathrm{~L} & 1 \\
\mathrm{~L} & \mathrm{~L} & \mathrm{~L} & \mathrm{~L} \\
0 & 1 & \mathrm{~L} & 0
\end{array}\right]_{k \times n} \quad(i=0, \mathrm{~L}, m)}
\end{aligned}
$$

We use $w_{i k}$ refer the right $k$ reviewers who evaluated the weight of the evaluation indicator $i$.

\section{THE EXAMPLE ANALYSIS AND VERIFICATION}

In the example analysis and verification the paper selected six of the public sector managers as evaluation objects. Respectively selected the tester's superiors, colleagues and subordinates as the assessors to evaluate and then based on Delphi method to determine the evaluator right.

We use a histogram showing the distribution of the weight of each index weights

Here are the rater weight distribution at the following: 
Table 1. Rater weight distribution.

\begin{tabular}{|c|c|c|c|c|}
\hline Assessors (Number) & Superior(2) & Colleague(3) & Subordinate(2) & Self-Assessment(1) \\
\hline \hline Weight & 0.18 & 0.12 & 0.10 & 0.08 \\
\hline
\end{tabular}

From the examples in this paper, the evaluation results are very satisfactory. It fully demonstrates the practical significance and feasibility of the evaluation model of management leadership, has the very good application prospect. At the same time, in the process of the use of the evaluation model, we also found some weakness. When the contestant is large, for the data processing is tedious that we must use the software to analyze.

\section{CONCLUSION}

This article combines fuzzy comprehensive evaluation method and analytic hierarchy process, with the help of the predecessors' research results, put forward on the premise of Public Sector Managers Leadership Model, and a case analysis was carried out. Leadership is a collection of multidimensional and multi-level concept, and this article uses the scientific quantitative mathematical method to qualitative relations, in the past the flaws of the traditional subjective qualitative evaluation is an effective improvement. Leadership is a new field of research, but which also has not caused widespread concern about the public sector. This article only gives the general public sector management competency in theory is scientific, reasonable and effective. And in the process of practice, the public sector to sector based on the actual situation, targeted to determine the indicators and weights, strengthen leadership evaluation of systemic and effectiveness.

\section{CONFLICT OF INTEREST}

The authors confirm that this article content has no conflict of interest.

\section{ACKNOWLEDGEMENTS}

This work is supported by 2013 scientific research project of Beifang University of Nationalities (2013XYZ021), institute of information and system computation science of Beifang University (13xyb01).

\section{REFERENCES}

[1] J.A. Andersen, "Public versus private managers: How public and private managers differ in leadership behavior," Public Administration Review, vol. 70, no.1, pp. 131-141, 2010.

[2] S. Fernandez, Y.J. Cho and J.L. Perry, "Exploring the link between integrated leadership and public sector performance," Leadership Quarterly, vol. 21, no.2, pp. 308-323, 2010.

[3] R.J. Boaden, "Leadership development: Does it make a difference?," Leadership and Organization Development Journal, vol. 27, no.1, pp. 5-27, 2005 .

[4] W. Chu, Y. Li, C. Liu, and W. Mou, 2014. "A manufacturing resource allocation method with knowledge-based fuzzy comprehensive evaluation for aircraft structural parts," International Journal Of Production Research, vol. 52, no. 11, pp. 3239-3258, 2014.

[5] R. Dilts, "Visionary Leadership Skills: Creating a World to Which People Want to Belong," Capitola, CA: Meta Publications, 1996.

[6] D. C. McClelland, "Testing for competence rather than for "intelligence," American Psychologist, no. 28, pp.1-14, 1973.

[7] L. Gun, J. Zoo, Y. Wang, T. S. Low, and K. Wang, "Comprehensive health condition assessment on partial sewers in a southern Chinese city based on fuzzy mathematic methods," Frontiers of Environmental Science \& Engineering, vol. 8, no.1, pp.144-150, 2014.

[8] T. Trottier, M. Van Wart, and X.H. Wang, "Examining the nature and significance of leadership in government organization," Public Administration Review, vol. 68, no.2, pp. 319-333, 2008.

[9] M. Onno, and I. Sylvia, "The role of moral leadership for sustainable production and consumption," Journal of cleaner production, vol. 63 , no. 2 , pp. $22-24,2014$

[10] D.C. Orazi, A. Turrini, and G. Valotti, "Investigating the link between public sector leadership and civil servants' performance," Paper presented at the 28th EGOS Colloquium, Helsinki, 2012.

Received: May 26, 2015

Revised: July 14,2015

Accepted: August 10,2015

(C) Zhang and Liu; Licensee Bentham Open.

This is an open access article licensed under the terms of the (https://creativecommons.org/licenses/by/4.0/legalcode), which permits unrestricted, noncommercial use, distribution and reproduction in any medium, provided the work is properly cited. 